\title{
INVENTARIOS DE MÚSICA. METODOLOGÍA PARA LA IDENTIFICACIÓN DE COMPOSICIONES Y EL ESTABLECIMIENTO DE CONCORDANCIAS: EL CASO DE LOS INVENTARIOS DE LA CAPILLA DE MÚSICA DE LA CATEDRAL DE MÁLAGA (1800-1836) Y LAS OBRAS EN CASTELLANO DE JAIME BALIUS ${ }^{1}$
}

\author{
INVENTORIES OF MUSICAL SOURCES. METHODOLOGY FOR THE \\ IDENTIFICATION OF COMPOSITIONS AND THE ESTABLISHMENT OF \\ CONCORDANCES: THE CASE OF THE INVENTORIES OF THE MUSIC \\ CHAPEL OF MALAGA CATHEDRAL (1800-1836) AND THE WORKS \\ IN SPANISH BY JAIME BALIUS
}

\author{
María José de la Torre Molina \\ Universidad de Málaga \\ mjdelatorre@uma.es \\ ORCID iD: https://orcid.org/0000-0002-1197-907X
}

\begin{abstract}
Resumen
Durante el primer tercio del siglo XIX, los músicos de la Capilla de la Catedral de Málaga redactaron doce inventarios, en los que se recogieron los bienes propiedad del conjunto. En su mayoría, composiciones musicales destinadas a las "funciones contratadas" (ceremonias para las que la agrupación actuaba contratada por comitentes distintos del Cabildo Catedralicio). El repertorio que los inventarios dejan entrever es muy variado: Hay en él creaciones de compositores extranjeros y de muchos de los maestros de Capilla más sobresalientes de la España de la época. Sin embargo, varios factores dificultan la identificación de autores y obras, así como el establecimiento de concordancias entre unos inventarios y otros. En este artículo se presentan una serie de estrategias destinadas a la superación de estos problemas. Se partirá del estudio de un caso concreto, el de las obras en castellano de Jaime Balius (1750-1822).
\end{abstract}

\begin{abstract}
In the course of the first third of the nineteenth century, members of the Capilla de Música of Málaga Cathedral compiled twelve inventories of their possessions. These mostly contain musical compositions to be performed in the so-called "funciones contratadas", ceremonies organized by patrons other than the Cabildo Catedralicio. The repertoire of the inventories is very varied, including works by composers such as Haydn and Mozart together with many of the foremost Spanish maestros de capilla of the eighteenth and the nineteenth centuries. However, the identification of both composers and compositions is not always easy, nor is the correspondence between the entries in different inventories. The aim of this article is to present some strategies which can be implemented in order to overcome these difficulties. Many of the examples are related to the particular case of works to Spanish texts by Jaime Balius (1750-1822).
\end{abstract}

1 El presente artículo está vinculado al Proyecto de Investigación "Poder, identidades e imágenes de ciudad: Música y libros de ceremonial religioso en la España meridional (siglos XVI-XIX)", HAR2015-65912-P (MINECO/FEDER). Quiero dejar constancia de mi agradecimiento al Profesor Iain Fenlon, por haber leído una versión preliminar de este trabajo y por sus orientaciones, sugerencias y consejos, que me han sido muy útiles y han contribuido a enriquecer este artículo. También debo agradecer a D. Alberto Palomo Cruz y a Dña. Susana Rodríguez de Tembleque, del Archivo del Cabildo Catedralicio de Málaga, las facilidades que siempre me han dado para el desarrollo de mis investigaciones. 


\author{
Palabras clave \\ Capillas musicales, catedral, siglo XVIII, siglo XIX, inventa- \\ rios, repertorio, Jaime Balius, obras en castellano, villancicos.
}

\section{INTRODUCCIÓN}

Durante el primer tercio del siglo XIX, la mayor parte de los músicos de la Capilla de la Catedral de Málaga actuaron en celebraciones religiosas organizadas por comitentes distintos al Cabildo de la iglesia mayor. Para cubrir adecuadamente las demandas musicales de estas ceremonias, denominadas en las fuentes "funciones contratadas", "funciones particulares" o "fiestas", los profesionales del conjunto se vieron obligados a adquirir una abundante cantidad de composiciones musicales. Este repertorio, acumulado a lo largo de los años, se recogió en un total de doce inventarios, que se elaboraron entre finales de 1800 y la década de 1830. Los doce listados mencionan una enorme variedad de composiciones, en latín y en castellano, obras de autores muy diversos, entre ellos Pergolesi, Haydn, Mozart y muchos de los maestros de capilla más destacados de la España peninsular de finales del siglo XVIII y principios del siglo XIX ${ }^{2}$.

La presentación de los principales rasgos del repertorio asociado a las "funciones contratadas" -un repertorio diferenciado del que se escuchaba en las ceremonias dependientes del Cabildo Catedralicio- ha sido objeto de otros trabajos ${ }^{3}$. Sin embargo, su análisis en profundidad está aún pendiente. Una investigación de estas características, además de proporcionar detalles concretos sobre autores y obras demandadas, sería fundamental para mejorar el cono-

2 Hasta fechas muy recientes estos inventarios habían sido objeto de escasa atención. El único estudio de conjunto que existe sobre los mismos es DE LA TORRE MOLINA (2016): 455-482, que incluye una relación de los inventarios de la Capilla, con las fechas de elaboración de cada uno de ellos y las fuentes en las que se plasmaron, entre otros detalles. En dos trabajos anteriores la misma autora analizó y editó el Inventario Capilla [8]: DE LA TORRE MOLINA (2009-2010): 239-279; (2011-2012): 149-176. Estos dos últimos artículos también contienen una explicación pormenorizada del significado de las expresiones homónimas «funciones contratadas», «funciones particulares» y «fiestas» y del significado de las expresiones «músicos hermanados» $\mathrm{y}$ «Capilla» en el contexto de estas celebraciones.

3 DE LA TORRE MOLINA (2016): 455-482; (2009-2010): 239 279; (2011-2012): 149-176. Sobre las diferencias existentes entre los inventarios de la Capilla y los inventarios del fondo catedralicio, vid. estos mismos artículos y DE LA TORRE MOLINA (2010a): 237-285. El único trabajo específico dedicado a los inventarios del fondo catedralicio es el de LLORDÉN (1969): 237-246.

\section{Key words}

Spanish Music, cathedral, eighteenth century, nineteenth century, inventories, music chapels, Jaime Balius, musical repertory, Spanish text, villancicos.

cimiento que tenemos de otros aspectos relacionados con la proyección urbana de las capillas de música catedralicias, en el tránsito del Antiguo al Nuevo Régimen; las relaciones existentes entre estos conjuntos y los cabildos de los que dependían y el papel de los maestros de capilla en la vida musical ciudadana. Cuestiones todas ellas tradicionalmente poco consideradas en las investigaciones sobre música catedralicia, pero muy relevantes para la comprensión del papel de las capillas, en los ámbitos institucional y urbano, y muy útiles para la superación de modelos de estudio excesivamente centrados en la estructura de estas agrupaciones y en la producción de sus maestros ${ }^{4}$.

Para analizar en profundidad el repertorio de las "funciones contratadas" de la capilla catedralicia malacitana, es imprescindible, primero, identificar las composiciones mencionadas en los distintos asientos de cada inventario y establecer posibles concordancias con asientos de los otros inventarios. Sólo así podría determinarse la constitución del repertorio en un momento concreto y reconstruir tanto los cambios sufridos por el mismo en el primer tercio del siglo XIX como las motivaciones subyacentes en ellos. Sin embargo, en el caso de los inventarios objeto de estudio la identificación de autores y composiciones es, a menudo, complicada. Sobre todo, por la variabilidad existente en el grado de detalle de los asientos -incluso entre los pertenecientes a un mismo inventario- y por las inconsistencias en los criterios y fórmulas empleadas para la mención de creadores, tipologías compositivas y obras concretas.

La presentación de estrategias encaminadas a la superación de las dificultades mencionadas es el objetivo del presente artículo. A lo largo del mismo, se analizarán los procedimientos empleados para: a. Trazar concordancias entre los asientos de los doce inventarios de la Capilla de Música de la Catedral de Málaga que se elaboraron en el primer tercio del siglo XIX y b. Establecer la autoría, el título y, cuando ha sido posible, la plantilla, la advocación y la fecha de adquisición, por parte del conjunto, de las obras que formaron parte de su repertorio durante ese período. Puesto que esta tarea es ingente (sólo con la información suministrada por los inventarios debe desarrollarse sobre un total de 855 asientos),

4 Vid. una reflexión sobre estas cuestiones en DE LA TORRE MOLINA (2010b): 299-341. 
he preferido ocuparme en este artículo de un compositor y de un repertorio concreto: Las obras en castellano de Jaime Balius (1750-1822).

Esta elección no es casual, aunque pueda resultar sorprendente: Balius ni fue miembro de la Capilla de Música de la Catedral de Málaga ni, hasta donde es posible conocer, consta que la dirigiese en ningún momento. Gran parte de su carrera se desarrolló en la Catedral de Córdoba, institución de la que fue Maestro de Capilla, primero en el período 17851787 y, de nuevo, entre 1789 y su muerte, en $1822^{5}$. Sin embargo, los inventarios estudiados mencionan más obras de Balius que de cualquiera de los maestros de capilla de la seo malacitana. En el caso de las obras en castellano, Balius es, junto con Esteban Redondo (segundo organista de la Catedral de Málaga), el autor al que los inventarios atribuyen más composiciones. Esta situación contrasta con el hecho de que, de los maestros de Capilla de la Catedral de Málaga, se cita una sola obra en castellano, un villancico de Jaime Torrens, pese a que una parte importante de la labor compositiva de Torrens -al igual que la de su predecesor, Juan Francés de Iribarren- se desarrolló en torno a este género ${ }^{6}$.

\section{LOCALIZACIÓN EN LOS INVENTARIOS DE LAS OBRAS EN CASTELLANO DE JAIME BALIUS}

El primer paso, lógico, para la identificación de las composiciones y el establecimiento de concordancias entre los distintos inventarios es la localización, en cada uno de ellos, de las obras en castellano atribuidas a Jaime Balius. No se trata de una mera labor de rastreo, ya que para que esta tarea pueda realizarse con garantías es importante tener en cuenta cuatro factores.

El primero, que los inventarios raramente aportan el nombre de pila de los compositores. Esto, unido a la falta generalizada de datos que permitan ubicar a los autores en un determinado entorno profesional, a menudo complica su identificación. Por ejemplo, entre las obras que el Inventario Capilla [8] atribuye simplemente a "García", probablemente hay composiciones de, al menos, cuatro creadores: Francis-

5 Sobre este autor, en especial sobre su etapa en la Catedral de Córdoba, vid. BEDMAR ESTRADA (2009). Sobre la trayectoria profesional de este músico y la recepción de sus obras en la Colegiata de Manresa, vid. también BALLÚS CASÓLIVA (2004).

6 Jaime Torrens fue Maestro de Capilla de la Catedral de Málaga entre 1770 y 1803 . Sobre este autor, vid. MARTÍN QUIÑONES (1999). Juan Francés de Iribarren ocupó el puesto entre 1733 y 1767: NARANJO (1999): vol. 5, 235-241. Sobre los posibles motivos de la escasez de obras de los maestros de Capilla de la Catedral de Málaga recogidas en los inventarios de composiciones propiedad del conjunto, vid. DE LA TORRE MOLINA (2016): 463-465. co Javier García "El Españoleto", Manuel García, Tomás García y Fabián García Pacheco"". También es necesario valorar la posible existencia de imprecisiones, inconsistencias o variantes caligráficas en la transcripción de los apellidos. Afortunadamente, en el caso de Balius estas diferencias son mínimas, pues se reducen a la variante "Valius".

El segundo aspecto a considerar es que, en ocasiones, las obras se relacionan con sus donantes, no con sus autores, lo que, unido a la ambigüedad en la redacción de algunos asientos, puede inducir atribuciones erróneas. Por ejemplo, de la lectura del Inventario Capilla [2] podría deducirse que José Blasco (tenor asalariado de la Catedral de Málaga) fue el autor de la Misa [2/10] "Copiar las voces de la Misa de don José Blasco 31 [reales]" Inventario Capilla [8] permite concluir que Blasco no compuso la obra, sino que la cedió para que la Capilla procediese a su adaptación y copia: [8/7] "Misa a dúo y a cuatro del Maestro Martínez, para dotaciones y [ceremonias] ordinarias [compuesta] en el año 1797 y [en] el [año] de 1801 costó a don José Blasco lo más [sic] y la Capilla pagó 31 reales"

Un tercer aspecto a tener en cuenta, en el rastreo de las composiciones en castellano de Jaime Balius en los inventarios de la Capilla, es que estas obras pueden aparecer en cualquier lugar, no necesariamente en los apartados que presumiblemente les corresponderían ni junto a otras obras similares. Pondré un ejemplo concreto: Los inventarios Capilla [1], [8] y [12] están organizados en distintos apartados, definidos por tipologías compositivas. El epígrafe "villancicos" del Inventario Capilla [12] -asientos [12/43]-[12/96]reúne la mayoría de las obras en castellano que se citan en

7 Vid. DE LA TORRE MOLINA (2010a). He usado el término "Capilla" en la denominación de los inventarios estudiados para diferenciarlos de los inventarios del fondo musical catedralicio, siguiendo el criterio establecido en DE LA TORRE MOLINA (2009-2010) y (2011-2012). El Inventario Capilla [8] comenzó a redactarse en 1806 y se realizaron añadidos en él hasta 1814: Libro de las Constituciones y acuerdos de la Capilla de Música de la Santa Iglesia Catedral de Málaga (manuscrito), Archivo del Cabildo Catedralicio de Málaga (ACCM), Legajo 785 , pieza $n^{\circ} 3$, ff. 18 r-24r.

8 Libro de las fiestas de la Capilla de Música de esta Santa Iglesia Catedral de Málaga (manuscrito), ACCM, Sección de Música, signatura 265-1, f. 9r. Para la numeración de los inventarios y de sus asientos he seguido las pautas detalladas en DE LA TORRE MOLINA (2009-2010); (2011-2012). El Inventario Capilla [2] recoge todas las obras adquiridas por la Capilla en 1801, año en el que José Blasco también ejerció como Mayordomo del conjunto. Sobre las funciones de los mayordomos de la Capilla de Música de la Catedral de Málaga y la relación existente entre este cargo y el correcto funcionamiento de las "funciones contratadas", vid. DE LA TORRE MOLINA (2003): vol. I, 139-143.

9 Libro de las Constituciones y acuerdos de la Capilla de Música de la Santa Iglesia Catedral de Málaga (manuscrito), ACCM, Legajo 785 , pieza $\mathrm{n}^{\mathrm{o}} 3$, f. 18r. Sobre la ubicación y fecha de elaboración del Inventario Capilla [2], vid. la nota supra. 
ese listado. Pero, a diferencia de lo que sucede en los inventarios Capilla [1] y [8], en Capilla [12] los gozos constituyen un apartado distinto -asientos [12/247]-[12/253]-, separado de los villancicos Además, otra de las obras en castellano, un aria de Balius, aparece dentro del epígrafe "motetes", probablemente porque este asiento se añadió en el segundo o tercer estrato de redacción de Capilla [12]. También incluye este listado otras piezas en castellano, fuera de los apartados "villancicos" y "gozos", al final del inventario, junto con obras diversas "que no estaban inventariadas por no estar probadas" -asientos [12/270]-[12/282]- ${ }^{10}$.

Un cuarto factor, relevante para la identificación de las composiciones y para el establecimiento de concordancias entre asientos de distintos listados, es que no todos los inventarios de la Capilla tienen la misma naturaleza ni se redactaron con la misma finalidad. Los inventarios Capilla [1] y [12] citan todas las obras que eran propiedad de la agrupación en el momento en el que esos listados se elaboraron. El Inventario Capilla [8] también es un inventario general, pero de él se excluyeron las composiciones que, por algún motivo, no se consideraban apropiadas para su interpretación en las "funciones contratadas". El resto de los inventarios, con la excepción de Capilla [3], recogen todas las piezas que el conjunto adquirió en un año en concreto, pero no el resto. El Inventario Capilla [3] lista todas las creaciones que se incorporaron al fondo de la agrupación en 1802 y, de forma no sistemática, también otras adquiridas con anterioridad ${ }^{11}$.
En su conjunto, los inventarios tienen un total de 32 asientos con composiciones en castellano atribuidas expresamente a Jaime Balius. Se reparten de la siguiente manera: Capilla [1] (5 asientos), Capilla [3] (6 asientos), Capilla [8] (11 asientos) y Capilla [12] (10 asientos). En el Apéndice 1 de este artículo puede verse el contenido de cada uno de estos asientos y constatar un detalle muy relevante para la búsqueda de concordancias entre ellos: Las seis obras en castellano de Balius que menciona el Inventario Capilla [3] fueron adquiridas en 1802, circunstancia que permite descartar vínculos entre ellas y los asientos con obras en castellano de Balius del Inventario Capilla [1], que fue finalizado el dos de enero de $1801^{12}$.

\section{CONCORDANCIAS BASADAS EN LOS TÍTULOS DE LAS COMPOSICIONES}

Una vez identificados los asientos con obras en castellano atribuidas a Jaime Balius, he comenzado a establecer concordancias tomando como referencia los títulos de las piezas, tal y como aparecen en cada inventario. Con este fin, he aislado, en primer lugar, los asientos que recogen el título de las composiciones: Un total de 13, de dos inventarios distintos, Capilla [8] y Capilla [12] (vid. Tabla 1).

\section{Inventario [8]}

$[8 / 171]$

$[8 / 180]$

$[8 / 181-182]$

$[8 / 183]$

$[8 / 187-188]$

$[8 / 198]$

$[8 / 212]$ $22^{\circ}$

Villan[ci ${ }^{\text {co }}$. a tres del señor Valius Los frios La escarcha, [para] segunda clase

$31^{\circ}$ Vill[anci $]^{\text {co }}$. a tres Ques [sic] esto, Maria del señor Balius, [para] primera y segunda [clases]

$32^{\circ}$ Dos $\mathrm{VV}^{\mathrm{s}}$. [villancicos] a cuatro: [el] primero Rindan Veneraciones [y el] segundo En blandas prisiones, del señor Balius, [para] primera y segunda clase

$33^{\circ} V^{\circ}$ ill[anci $]^{\text {co }}$. a cuatro Manjar Delicioso, del señor Balius, [para] primera y segunda [clases]

$36^{\circ}$ Dos Vill[anci $]^{\text {cos }}$. a cuatro: el primero El cielo se pasma [y el] segundo Alegres festivos, del señor Balius, [para] primera y segunda clase

$43^{\circ} \quad$ Vill $[a n c i]^{\text {co }}$. a cuatro Hafligido ambriento, del Maestro Balius, para primera clase

$56^{\circ}$
0010

0012

0016

0012

0020

0020

0012
10 Libro de las Constituciones y acuerdos de la Capilla de Música de la Santa Iglesia Catedral de Málaga (manuscrito), ACCM, Legajo 785 , pieza $\mathrm{n}^{\circ} 3$, f. [33]v.

11 Sobre las diferencias existentes en el contenido y finalidad de los inventarios de la Capilla, la distinción entre inventarios generales e inventarios parciales y las fechas de elaboración y añadidos realizados en cada inventario, vid. DE LA TORRE MOLINA (2016).
12 Cfr. Libro de las fiestas de la Capilla de Música de esta Santa Iglesia Catedral de Málaga (manuscrito), ACCM, Sección de Música, signatura 265-1, ff. 2v (firmas de recepción del Inventario Capilla [1]) y 18r (encabezado del Inventario Capilla [3]). 


\section{Inventario [12]}

$\begin{array}{lll}{[12 / 47]} & 5^{\circ} & \text { Vallansico [sic] a cuatro del Maestro Balius. Afligido } \\ {[12 / 78]} & 34^{\circ} & \text { Villansico a cuatro del Maestro Balius. Manjar. } \\ {[12 / 79]} & 35^{\circ} & \text { Villansico a tres del Maestro Balius. Que es esto Maria } \\ {[12 / 88]} & 43^{\circ} & \text { Villansico a cuatro del Maestro Balius. Alegrate, festivos }\end{array}$

Tabla 1.- Inventarios Capilla [1]-[12]. Obras en castellano de Jaime Balius. Asientos que recogen títulos de manera expresa ${ }^{13}$

A continuación, he buscado similitudes entre los asientos localizados. Para ello, he tenido en cuenta que la manera de consignar los títulos no tiene por qué ser la misma en todos los listados, dada la distancia cronológica que media entre ellos y la participación de distintas personas en su elaboración. En algunos casos, las diferencias se reducen a pequeñas variantes caligráficas y de puntuación: [8/180] "Ques esto, Maria" / [12/79] "Que es esto Maria". En otros casos, se modifican o se añaden y/o suprimen palabras: [8/198] "Hafligido hambriento" / [12/47] "Afligido".
Mediante este trabajo de cotejo, he podido establecer concordancias para ocho de los trece asientos que informan de los títulos de las composiciones e identificar un total de nueve obras en castellano de Jaime Balius. La Tabla 2 recoge los resultados de esta comparativa. En ella figuran, en primer lugar, los títulos normalizados de las piezas y su plantilla. A continuación, el número de asiento y la forma en la que se citan, literalmente, en cada inventario ${ }^{14}$.

Afligido hambriento. Villancico a cuatro

[8/198]: "Vill[anci] $]^{\text {co }}$ a cuatro Hafligido ambriento, del Maestro Balius, para primera clase".

[12/47]: "Villansico a cuatro del Maestro Balius. Afligido".

Alegres festivos. Villancico a cuatro

[8/188]: "[8/187-188] Dos Vill[anci] ${ }^{\text {cos }}$. a cuatro: el primero El cielo se pasma [y el] segundo Alegres festivos, del señor

Balius, [para] primera y segunda clase".

[12/88]: "Villansico a cuatro del Maestro Balius. Alegrate [sic] festivos.

El cielo se pasma. Villancico a cuatro

[8/187]: “[8/187-188] Dos Vill[anci] ${ }^{\text {cos }}$ a cuatro: el primero El cielo se pasma [y el] segundo Alegres festivos, del señor

Balius, [para] primera y segunda clase".

\section{En blandas prisiones. Villancico a cuatro}

[8/182]: "[8/181-182] Dos VV'. [villancicos] a cuatro: [el] primero Rindan Veneraciones [y el] segundo En blandas prisiones, del señor Balius, [para] primera y segunda clase".

13 Para la edición de los asientos en las tablas $1,3,4$ y 5 y en la tabla del Apéndice 1 se han seguido los siguientes criterios: En primer lugar, entre corchetes, figura el número que he asignado a cada asiento, de acuerdo con el sistema seguido en DE LA TORRE MOLINA (2009-2010); (2011-2012). A continuación, aparece en la tabla: el número dado a cada asiento por los autores de los inventarios (algo que no se hizo en todos los listados); el contenido de cada asiento (se han respetado los subrayados, los tachados y la ortografía originales y no se han resuelto las abreviaturas) y, por último, cuando el inventario lo menciona, la cantidad invertida en la compra y/o copia de cada composición o la valoración económica de los materiales de cada obra que realizaron el Mayordomo y los Comisionados de la Capilla.
14 Para normalizar los títulos de las composiciones, he tomado como referencia el asiento con información más precisa y he actualizado la ortografía. En el apartado 4 de este artículo y en el Apéndice 1 he relacionado las composiciones en castellano de Balius mencionadas en los inventarios Capilla [1]-[12] con obras del compositor que se conservan en la actualidad en la Sección de Música del ACCM. 
Los fríos, la escarcha. Villancico a tres

[8/171]: "Villan[ci] ${ }^{\mathrm{co}}$. a tres del señor Valius Los frios La escarcha, [para] segunda clase".

Manjar delicioso. Villancico a cuatro [al Santísimo]

[8/183]: "Vill[anci] ${ }^{\text {co }}$. a cuatro Manjar Delicioso, del señor Balius, [para] primera y segunda [clases]".

[12/78]: "Villansico a cuatro del Maestro Balius. Eleielo se pasma. Manjar".

¿Qué es esto, María? Villancico a tres

[8/180]: "Vill[anci] ${ }^{\mathrm{co}}$. a tres Ques [sic] esto, Maria del señor Balius, [para] primera y segunda [clases]".

[12/79]: "Villansico a tres del Maestro Balius. Que es esto Maria".

Rindan veneraciones. Villancico a cuatro

[8/181]: “[8/181-182] Dos $\mathrm{VV}^{\text {s. }}$ [villancicos] a cuatro: [el] primero Rindan Veneraciones [y el] segundo En blandas prisiones, del señor Balius, [para] primera y segunda clase".

Sacro convite. Villancico a dúo

[8/212]: "Vill[anci] ${ }^{\text {co }}$ a dúo Sacro Combite, del Maestro Balius, [para] segunda clase".

Tabla 2.- Inventarios [1]-[12]. Obras en castellano de Jaime Balius.

Composiciones identificadas y concordancias basadas en los títulos de las piezas

A partir de aquí, pueden plantearse al menos tres cuestiones: La primera, si es posible identificar más obras en castellano, pertenecientes al fondo de la Capilla y atribuidas a Balius, aunque su título no se recoja en ninguno de los listados. La segunda, si, en el caso de que esta identificación fuese posible, podrían establecerse posibles concordancias entre los asientos que mencionan dichas piezas. La tercera, si la Capilla pudo contar con otras composiciones en castellano de Balius, aunque su autoría no esté recogida de manera expresa en los inventarios, y cómo sería posible detectarlas.

\section{CONCORDANCIAS BASADAS EN LA TIPOLOGÍA, LA PLANTILLA Y LA ADVOCACIÓN DE LAS OBRAS}

He iniciado esta fase del trabajo identificando cuáles son los asientos que informan de la plantilla de las composiciones y agrupándolos de acuerdo con este parámetro (vid. tablas 3-5), para analizar después posibles similitudes y relaciones entre ellos.

Como puede verse en la Tabla 3, cada uno de los tres inventarios generales recogen una sola obra en castellano a dos voces de Jaime Balius. Sin embargo, la utilización de fórmulas tan distintas en la denominación de su tipología (dúo, villancico y aria, respectivamente) genera dudas acerca de si realmente se trata de la misma composición e incluso sobre si [1/107] estaba o no en castellano ${ }^{15}$.
[1/107]

$[8 / 212] \quad 56^{\circ}$

$[12 / 172] \quad 62$
Un Duo al Sacramento de Balius

Vill[anci]co. a duo Sacro Combite, del Maestro Balius, [para] segunda clase 0012

Aria a duo de Balius

Tabla 3.- Inventarios [1]-[12]. Obras en castellano a dos voces de Jaime Balius 
$[1 / 105]$

$[1 / 106]$

$[8 / 171$

[8/180]

$[12 / 45]$

[12/79]
Uno [un villancico] a tres a la Virgen, del Maestro Balius

Otro [villancico] a tres de Balius $22^{\circ} \quad$ Villan[ci] ${ }^{\text {co }}$. a tres del señor Valius Los frios La escarcha, [para] segunda clase

0010

Vill[anci]co. a tres Ques [sic] esto, Maria del señor Balius, [para] primera y segunda [clases]

0012

$3^{\circ} \quad$ Villansico a tres del Maestro Balius

$35^{\circ} \quad$ Villansico a tres del Maestro Balius. Que es esto Maria

Tabla 4.- Inventarios [1]-[12]. Obras en castellano a tres voces de Jaime Balius

Los inventarios Capilla [1], [8] y [12] mencionan, cada uno, dos villancicos a tres voces de Balius.

En el apartado anterior, basándome en la información proporcionada por los listados sobre los títulos de las composiciones, identifiqué tres de los seis asientos con villancicos a tres voces de Balius: Los fríos, la escarcha [8/171] y ¿Qué es esto, María? [8/180]-[12/79] (vid. Tabla 2). La coincidencia de plantilla y la advocación a la Virgen sugiere una posible relación entre el asiento [1/105] "Uno [un villancico] a tres a la Virgen, del Maestro Balius” y ¿Qué es esto, María? [8/180]-[12/79]. Esto hace plausible la concordancia entre el otro villancico a tres voces del Inventario Capilla [1] y Los fríos, la escarcha [8/171]. Por exclusión, y siguiendo el principio del probable mantenimiento de las obras en el repertorio -y por consiguiente en los inventarios generalestambién podría identificarse con Los fríos, la escharcha el villancico a tres voces del asiento [12/45] (vid. Tabla 4). En conclusión, los villancicos a tres voces de Balius citados en los inventarios generales podrían ser ¿Qué es esto, María? [1/105]-[8/180]-[12/79] y Los fríos, la escarcha [1/106][8/171]-[12/45].

La identificación de las obras en castellano a cuatro voces resulta mucho más complicada: Mientras que el Inventario Capilla [1] sólo menciona un villancico con esta plantilla, los inventarios Capilla [8] y [12] recogen, respectivamente, ocho y siete composiciones de estas características (vid. Tabla 5).
$[1 / 104]$

$[8 / 178]$

$[8 / 181-182] \quad 32^{\circ}$

$[8 / 183] \quad 33^{\circ}$

$[8 / 187-188] \quad 36^{\circ}$

$[8 / 198] \quad 43^{\circ}$

$[8 / 216] \quad 60^{\circ}$
Villan $[\mathrm{ci}]^{\mathrm{co}}$. a cuatro al Sacramento de Balius

Coplas a la Virgen de los Dolores a cuatro voces, del señor Balius, para primera y segunda clase

0016

Dos $\mathrm{VV}^{\mathrm{s}}$. [villancicos] a cuatro: [el] primero Rindan Veneraciones [y el] segundo En

blandas prisiones, del señor Balius, [para] primera y segunda clase

0016

Vill[anci $]^{\mathrm{co}}$. a cuatro Manjar Delicioso, del señor Balius, [para] primera y segunda [clases]

0012

Dos Vill[anci] ${ }^{\text {cos }}$. a cuatro: el primero El cielo se pasma [y el] segundo Alegres festivos, del señor Balius, [para] primera y segunda clase

Vill $[\text { anci }]^{\text {co }}$. a cuatro Hafligido ambriento, del Maestro Balius, para primera clase $\quad 0020$

Gozos a cuatro al señor San José del Maestro Balius, [para] primera y segunda clase 0016 


$\begin{array}{lll}{[12 / 47]} & 5^{\circ} & \text { Vallansico [sic] a cuatro del Maestro Balius. Afligido } \\ {[12 / 49-50]} & 7^{\circ} & \text { Dos villansicos del Maestro Balius a cuatro } \\ {[12 / 78]} & 34^{\circ} & \text { Villansico a cuatro del Maestro Balius. Eteielo se pasma. Manjar } \\ {[12 / 88]} & 43^{\circ} & \text { Villansico a cuatro del Maestro Balius. Alegrate, festivos } \\ {[12 / 247]} & 1 & \text { Gozos a cuatro de Balius } \\ {[12 / 248]} & 2 & \text { Coplas a cuatro de Balius }\end{array}$

Tabla 5.- Inventarios [1]-[12]. Obras en castellano a cuatro voces de Jaime Balius

En el apartado anterior, pude establecer concordancias para seis de los dieciséis asientos con obras en castellano a cuatro voces de Balius e identificar tres de las composiciones que refieren: Alegres festivos [8/188]-[12/88], Afligido hambriento [8/198]-[12/47] y Manjar delicioso [8/183]-[12/78] (vid. Tabla 2). El reto es encontrar vínculos entre los diez asientos restantes.

Si comparamos la cantidad de obras en castellano a cuatro voces de Jaime Balius en el Inventario Capilla [1] y las que se mencionan en el Inventario Capilla [8], debemos concluir que entre 1801 y 1806-1814 el conjunto debió de adquirir, al menos, siete piezas del compositor con estas características (vid. Tabla 5). La identificación de esas siete piezas podría ser un punto de partida para el establecimiento de concordancias para los diez asientos que no parecen relacionados entre sí e, incluso, para otros asientos, sin información sobre plantilla, que refieren obras en castellano de Balius.

El análisis de los inventarios Capilla [2]-[7], que recogen las obras adquiridas por el conjunto entre 1801 y 1806, permite rastrear la entrada en el fondo de la agrupación de seis piezas en castellano de Balius: Los cuatro villancicos [3/7-10] y los "Dos gozos del Maestro Balius a San José regalados por el señor [Pedro] Despax" [3/52-53] ${ }^{16}$.

No es posible determinar cuáles fueron los cuatro villancicos [3/7-10], cuyo título, plantilla y advocación no precisa el inventario Capilla [3], ni, en consecuencia, relacionarlos con los que se mencionan en los inventarios Capilla [8] y [12]. Sí es posible, en cambio, construir hipótesis viables para los gozos [3/52-53] por medio de un procedimiento que también puede aplicarse a las Coplas a la Virgen de los Dolores [8/178].

Comenzaré por las coplas. La plantilla vocal y la advocación facilitan el trazado de una posible concordancia entre [8/178] y [1/102] "[1/102-103] Dos de Dolores de Balius y Redondo", ya que ni el Inventario Capilla [1] ni el Inventario

16 Vid. el Apéndice 1 de este trabajo.
Capilla [8] parecen recoger más obras en castellano a cuatro voces de Balius dedicadas a la Virgen de los Dolores (vid. Tabla 5). El tipo de pieza y la plantilla vocal también permiten vincular los asientos [8/178] "Coplas a la Virgen de los Dolores a cuatro voces, del señor Balius" y [12/248] "Coplas a cuatro de Balius". Ambos son los únicos con "coplas" a cuatro voces en sus respectivos inventarios.

Los inventarios Capilla [8] y [12] listan unos únicos gozos a cuatro voces de Balius dedicados a San José, [8/216] y [12/247] respectivamente. La advocación sugiere un posible nexo con uno de los gozos [3/52-53] "Dos gozos del Maestro Balius a San José regalados por el señor Pedro Despax". Pero, aparentemente, resulta imposible discernir con cuál de ellos, al no especificar [3/52-53] la plantilla de las piezas. No obstante, hay un detalle, el del donante, que puede aclarar la cuestión: En el asiento doble [8/185-186] se mencionan unos "Gozos a San José a tres por don P.D.B. para primera y segunda y sirven para San Antonio por tener las voces duplicadas". Podría concluirse que "P.D.B." fue el autor de la pieza y, aunque no se especifica a quién corresponden esas iniciales, no es difícil relacionarlas con Pedro Despax y Beltri, violón y contrabajo de la Capilla de Música de la Catedral de Málaga. Sin embargo, como he señalado anteriormente, debemos ejercer cierta sospecha en los casos en los que los asientos parecen atribuir obras a los músicos de la Catedral de Málaga ${ }^{17}$ : Es probable que Despax no fuese el compositor de los gozos [8/185-186], sino su donante. De ser así, podrían establecerse concordancias entre el asiento [8/185-186] y los gozos [3/52-53], también regalados por él. En otras palabras, la Capilla pudo contar con unos Gozos a San José a cuatro voces [3/53]-[8/216]-[12/247] y con unos Gozos a tres voces [3/52]-[8/185-186], susceptibles de interpretarse en ceremonias dedicadas a San José y a San Antonio. Incluso podría aventurarse una concordancia entre estos últimos y los recogidos en el asiento [12/252] "Id. [gozos] a seis tres sin autor": En la primera redacción del asiento 
[12/252], se consignaron unos únicos gozos, a seis voces, sin autor. Sin embargo, en el segundo o tercer estrato de redacción se tachó la palabra "seis" y se sustituyó por "tres". El error pudo deberse a la existencia de un juego doble de voces (uno dedicado a San José y otro a San Antonio), que el autor del primer estrato quizás confundió con un solo juego a seis. La omisión del nombre del autor pudo deberse a que el Inventario Capilla [12] se hizo tomando como modelo el Inventario Capilla [8], que no nombraba a Balius, sino a P.D.B ${ }^{18}$.

Coplas a cuatro voces a la Virgen de los Dolores

[1/102]: "[1/102-103] Dos de Dolores de Balius y Redondo".

[8/178]: "Coplas a la Virgen de los Dolores a cuatro voces, del señor Balius, para primera y segunda clase".

[12/248]: "Coplas a cuatro de Balius".

\section{Gozos a tres a San Antonio}

[8/186]: “[8/185-186] "Gozos a San José a tres por don P.[edro] D.[espax] y B.[eltri] [sic], para primera y segunda [clases], y sirven para San Antonio por tener las voces duplicadas".

1827 [12/252]: "Id. [gozos] a seis tres sin autor".

\section{Gozos a tres a San José}

[3/52]: "[3/52-53] Dos gozos del Maestro Balius a San José regalados por el señor [Pedro] Despax".

[8/185]: "[8/185-186] "Gozos a San José a tres por don P.[edro] D.[espax] y B.[eltri] [sic], para primera y segunda [clases], y sirven para San Antonio por tener las voces duplicadas".

[12/252]: "Id. [gozos] a seis tres sin autor". Posteriormente, a lápiz, se tachó "seis" y se escribió en su lugar "tres [voces]".

\section{Gozos a cuatro a San José}

[3/53]: “[3/52-53] Dos gozos del Maestro Balius a San José regalados por el señor [Pedro] Despax”.

[8/216]: "Gozos a cuatro al señor San José del Maestro Balius, [para] primera y segunda clase".

[12/247]: "Gozos a cuatro de Balius".

Los fríos, la escarcha. Villancico a tres

[1/106]: "Otro [villancico] a tres de Balius".

[8/171]: "Villan[ci] ${ }^{\text {co }}$ a tres del señor Valius Los frios La escarcha, [para] segunda clase".

[12/45]: "Villansico a tres del Maestro Balius".

¿Qué es esto, María? Villancico a tres

[1/105]: "Uno [un villancico] a tres a la Virgen, del Maestro Balius".

[8/180]: "Vill[anci] ${ }^{\text {co }}$ a tres Ques [sic] esto, Maria del señor Balius, [para] primera y segunda [clases]".

[12/79]: "Villansico a tres del Maestro Balius. Que es esto Maria".

Tabla 6.- Inventarios [1]-[12]. Obras en castellano de Jaime Balius. Composiciones identificadas y concordancias establecidas a partir de información sobre tipología, plantilla y advocación ${ }^{19}$

18 Pedro Despax murió en agosto de 1804: Libro de las fiestas, f. 49v (nota sobre la mayordomía y los músicos muertos en la epidemia de 1804). Los autores de la primera fase de redacción del Inventario Capilla [12] -Francisco Gutiérrez (mayordomo en 1827) y los dos comisionados para la revisión de las composiciones (Mateo Vasallo y José María Velasco)- no entraron en la Capilla hasta mucho más tarde. No coincidieron en ella con Despax y no tenían por qué relacionar las ini- ciales "P.D.B." con él. En 1827 tampoco vivían ya los dos mayordomos que podían haber aclarado tanto la autoría de la composición como la identidad del donante: José Laure -mayordomo en 1802, año en el que Despax cedió los gozos [3/52-53]- murió en 1804 y José Blasco -autor del Inventario Capilla [8]- falleció en 1814: Libro de las fiestas de la Capilla de Música de esta Santa Iglesia Catedral de Málaga (manuscrito), ACCM, Sección de Música, signatura 265-1, ff. 49v (nota sobre la mayordomía y los músicos muertos en la epidemia de 1804) y $134 \mathrm{v}$ (nota).

19 Para la normalización de los títulos de las composiciones he seguido el mismo procedimiento descrito para la Tabla 2 (vid. supra). 


\section{CONCORDANCIAS ESTABLECIDAS A PARTIR DEL ANÁLISIS DE OTRAS FUENTES}

Una vez agotadas las estrategias de identificación y establecimiento de concordancias, basadas en el análisis y en la comparación de la información ofrecida por los asientos, es necesario recurrir al análisis y al cruce de los datos ofrecidos por otras fuentes. Fundamentalmente de dos tipos: a. El Libro de las Constituciones y el Libro de las fiestas, que se generaron para afrontar los retos normativos, organizativos y ceremoniales que plantearon las "funciones contratadas" 20 , y b. Los materiales que se conservan de composiciones musicales aparentemente mencionadas en los inventarios. Los resultados de dicho estudio no siempre resultan concluyentes, pero sí permiten confirmar algunas hipótesis y descartar algunas concordancias posibles.

En el apartado anterior detallé cómo las diferencias existentes en la definición de la tipología de las composiciones de los asientos [1/107], [8/212] y [12/72] -que mencionan una obra a dos voces de Jaime Balius denominada "dúo", "villancico" y "aria", respectivamente- dificultaban el establecimiento de una posible relación entre ellos. El Catálogo del ACCM aparentemente no resulta de ayuda para la resolución de este problema, pues no recoge ninguna obra con título similar a [8/212] "Villancico a dúo Sacro convite" ${ }^{21}$. Sin embargo, el análisis de los materiales de las composiciones en castellano conservadas de Balius, en la Sección de Música del ACCM, permite la identificación de [8/212] con el catalogado con el nombre de ;Oh prodigio!

Segunda clase/ año 1806 [sic]/ Villancico / Recitado y Aria a dúo / de alto y tenor / al Santísimo / Sacro Convite de Jesu - Christo/ con violines, oboes, trompas y bajo / del Maestro don Jayme Balius / O prodigio / Lo regaló Don Pedro Despax y Beltry / siendo Mayordomo don José Laure ${ }^{22}$.

La denominación "recitado y aria a dúo", que aparece en la particella, y la advocación "al Santísimo" refuerzan la filiación [1/107]-[8/212]-[12/272]. Pero la fecha, 1806, parece desmentir ese vínculo, al menos en el caso de [1/107], ya que la redacción del Inventario Capilla [1] se dio por aca-

20 Op. cit., vid. supra.

21 Libro de las Constituciones y acuerdos de la Capilla de Música de la Santa Iglesia Catedral de Málaga (manuscrito), ACCM, Legajo 785, pieza ${ }^{\circ} 3$, y Libro de las fiestas de la Capilla de Música de esta Santa Iglesia Catedral de Málaga (manuscrito), ACCM, Sección de Música, signatura 265-1. segunda. bada mucho antes de ese año ${ }^{23}$. Aún así, hay dos aspectos que hacen viable la concordancia [1/107]-[8/212]-[12/272]. El primero, que en la portadilla citada también se recoge que la pieza fue cedida por Pedro Despax durante la mayordomía de José Laure. Tanto Despax como Laure murieron en agosto de 1804 , a consecuencia de la epidemia de fiebre amarilla que asoló Málaga ${ }^{24}$. Por lo tanto, 1806 no puede ser el año de composición de Sacro convite ni el año de la entrada de la obra en el fondo de la Capilla. Un segundo aspecto a destacar es que el ACCM custodia un número elevado de partituras y particellas en cuyas portadillas y/o encabezados figura "1806", pese a que fueron adquiridas por la Capilla con anterioridad a esa fecha. Al menos en el caso de los materiales de las obras en castellano de Balius, todas las anotaciones "1806" tienen caligrafía de José Blasco, por lo que parece razonable pensar que esa marca puede corresponder, en realidad, a la fecha de revisión e inclusión de las obras en el Inventario Capilla [8], cuya primera fase de elaboración, al frente de la cual estuvo Blasco, comenzó precisamente ese año ${ }^{25}$.

La Sección de Música del ACCM custodia unos únicos gozos de Jaime Balius, Pues sois santo sin igual. El análisis de los materiales de la composición confirma que Pedro Despax no fue su autor y permite establecer una correspondencia con los gozos [8/185-186]:

Primera y segunda clase[.] Año 1806/ Gozos a 4 voces/ con violines, flautas, trompas y bajo/ del Maestro Don Jayme Balius/ Al Señor San José/ Los regaló a la Capilla Don Pedro Despax y Beltriy [sic]/ siendo Mayordomo/ don José Laure ${ }^{26}$.

En apariencia, la fecha que figura en la portadilla, 1806, impide relacionar los gozos [8/185-186] con los gozos [3/53], ya que el Inventario Capilla [3] recoge las obras adquiridas en 1802, junto con algunas otras incorporadas antes de esa

23 Libro de las fiestas de la Capilla de Música de esta Santa Iglesia Catedral de Málaga (manuscrito), ACCM, Sección de Música, signatura $265-1$, ff. $1 \mathrm{v}-2 \mathrm{v}$.

24 Sobre los fallecimientos de Pedro Despax y José Laure, vid. Libro de las fiestas de la Capilla de Música de esta Santa Iglesia Catedral de Málaga (manuscrito), ACCM, Sección de Música, signatura 265-1, f. 49r (nota sobre la mayordomía y los músicos muertos en la epidemia de 1804).

25 Vid. infra en este artículo otros casos similares: Los gozos a cuatro voces Pues sois santo sin igual, el villancico Afligido hambriento y, en nota al pie, el villancico ¿Qué es esto, María? Las obras de Balius no son las únicas en las que la anotación "1806" no hace referencia ni al año de composición ni al de adquisición: vid. más ejemplos y los problemas que esta anotación ha supuesto para la catalogación de las composiciones en DE LA TORRE MOLINA (2008): 215-237; (2010).

26 ACCM, Sección de Música, signatura 10-5, portadilla de la particella del acompañamiento instrumental. 
fecha. Sin embargo, la particella de Pues sois santo sin igual también informa de que Pedro Despax cedió la pieza durante uno de los períodos en los que José Laure ejerció la mayordomía (es decir, necesariamente antes de mediados de 1804). Pudo ser, por ejemplo, en 1802, año en el que Laure fue mayordomo y en el que la Capilla recepcionó los gozos [3/52$53]^{27}$. Por lo tanto, al igual que sucede con ;Oh prodigio! - Sacro convite, 1806 debió de ser la fecha en la que estos gozos se evaluaron, para determinar la conveniencia de mantenerlos en el repertorio y la solemnidad de las ceremonias en las que podían interpretarse ("primera y segunda clase"). Las diferencias caligráficas entre las anotaciones "Primera y segunda clase[.] Año 1806" -realizadas por José Blasco, autor de Inventario Capilla [8]- y el resto de las que aparecen en la portadilla de la obra apoyan este razonamiento.

En el apartado anterior mencionaba las dificultades existentes para relacionar la única obra en castellano a cuatro voces de Balius recogida en el Inventario Capilla [1], el villancico [1/104], con las obras en castellano con esta plantilla mencionadas en el Inventario Capilla [8] y llegué a la conclusión de que [1/104] debía de ser uno de estos seis villancicos: Afligido hambriento [8/198]-[12/47], Alegres festivos [8/188]-[12/88], El cielo se pasma [8/187], En blandas prisiones [8/182], Manjar delicioso [8/183]-[12/78] y Rindan veneraciones [8/181]. Sin embargo, el análisis de los materiales conservados en el ACCM de Afligido hambriento permite descartar la concordancia entre este villancico y el asiento [1/104]. También, la relación entre Afligido hambriento y los villancicos [3/7-10], pues el primero fue incorporado al repertorio del conjunto después de 1802 :

[Afligido hambriento] Primera clase + año 1806 / Villancico a cuatro / con / violines, oboes, trompas / y. / bajo / Maestro / Don Jaime Valius / año de / 1805 / Regalado a esta Capilla de Málaga por el / señor don Francisco Berdejo, individuo de ella / En septiembre de 1806 años $^{28}$.

La portadilla de Afligido hambriento parece dar información contradictoria sobre la datación de la obra, ya que en ella se mencionan dos años: 1805 y 1806 . Para aclarar el sig-

27 Sobre la elección de Laure como Mayordomo de 1802 y su desempeño del cargo a lo largo de esa anualidad, desempeño que incluyó la redacción del Inventario Capilla [3], vid. Libro de las fiestas de la Capilla de Música de esta Santa Iglesia Catedral de Málaga (manuscrito), ACCM, Sección de Música, signatura 265-1, ff. 9v (Junta de Capilla, 07.01.1802) y 18r (Inventario Capilla [3]) y Libro de las Constituciones y acuerdos de la Capilla de Música de la Santa Iglesia Catedral de Málaga (manuscrito), ACCM, Legajo 785, pieza n ${ }^{\circ} 3$, ff. 6r-6v (Junta de Capilla, 14.08.1803) y 7r-8r (Junta de Capilla, 02.10.1803). trumental. nificado de estas referencias, es necesario acudir tanto a los inventarios como a otras fuentes de la Capilla, relacionadas con las "funciones contratadas".

Si Francisco Berdejo hubiese regalado la composición en 1806, la entrada debería haberse registrado en el Inventario Capilla [7], que recoge las obras adquiridas por la agrupación durante ese año. Sin embargo en este listado sólo aparecen obras en latín. Tampoco el Libro de las fiestas, en el que los mayordomos de la Capilla anotaron todas las "funciones contratadas" en las que participó la Capilla -junto con algunos detalles relevantes de las mismas-informa de ninguna ceremonia celebrada entre septiembre y diciembre de 1806 en la se estrenase obra alguna ni en las que hubiese gastos extraordinarios, que puedan relacionarse con la copia de materiales cedidos.

El Libro de las fiestas sí recoge, en cambio, cómo en septiembre de 1806 se trasladaron los papeles propiedad de la Capilla "desde la Catedral a la casa del Mayordomo, para que los revisen los comisionados y formar inventario [...]"29. Es decir, la aclaración "en septiembre de 1806 años", de la portadilla de Afligido hambriento, probablemente se refiere al momento en el que la pieza fue evaluada para determinar su inclusión en la primera fase de redacción del Inventario Capilla [8]. Es plausible, por lo tanto, que Berdejo donase el villancico en 1805 y que, por consiguiente, la entrada se anotase en el Inventario Capilla [6], que lista las obras adquiridas ese año.

El Inventario Capilla [6] no cita ninguna obra de Balius, pero sí asientos con obras en castellano sin atribución de autoría, que podrían corresponder con Afligido hambriento: [6/5-8] "Más por la composición de los cuatro villancicos para las fiestas de la Beata Verónica en las Capuchinas, papel de borrador, copia de los dichos y papel" y [6/16-19] "Más copia y papel de los acompañamientos de cuatro villancicos para el órgano o contrabajo para las fiestas de la Corona en San Agustín y de los Escribanos en la Victoria”. Las piezas [6/5-8] son probablemente obra de Esteban Redondo, pues el Libro de las fiestas recoge un pago de 50 reales a este compositor "por la composición de villancicos", gasto que aparece vinculado a las celebraciones realizadas en el Convento de las Capuchinas en agosto de $1805^{30}$. En cambio,

29 Libro de las fiestas de la Capilla de Música de esta Santa Iglesia Catedral de Málaga (manuscrito), ACCM, Sección de Música, signatura 265-1, f. 83r (Misa en el Convento del Ángel, 29.09.1806).

30 Libro de las fiestas de la Capilla de Música de esta Santa Iglesia Catedral de Málaga (manuscrito), ACCM, Sección de Música, signatura 265-1, f. 65r-65v (funciones del 10-11.08.1805). Al menos uno de los villancicos debió de estrenarse la tarde del 10 de agosto, en la "fiesta" con "Te Deum, sinfonía y villancico. Después, salve y letanía". El resto de las celebraciones fueron una Misa (oficiada en la mañana del 
en la partida de los villancicos [6/16-19] sólo se reflejan los gastos derivados de la copia de los materiales, lo que apunta a una posible cesión de las piezas (en estos casos, lo habitual es que el conjunto abonase al menos una parte del importe del papel y de la copia $)^{31}$.

Excluido Afligido hambriento, desafortunadamente no es posible ir más allá en la identificación de [1/104]: El villancico En blandas prisiones [8/182]-[12/50] ni se conserva en el ACCM ni se menciona en otras fuentes de la Capilla y el análisis de las particellas de Alegres festivos [8/188]-[12/88], El cielo se pasma [8/187], Manjar delicioso [8/183]-[12/78] y Rindan veneraciones [8/181] tampoco arroja luz sobre la cuestión. Todos concuerdan con la descripción ofrecida por [1/104], es decir, plantilla a cuatro voces y dedicación al Santísimo Sacramento:

Villancico a cuatro al Santísimo Santo [sic] / con violines, oboes y trompas / Alegres festivos / Para el archivo de esta Santa Iglesia / Del Maestro Balius / Año de $1797^{32}$.

Villancico a cuatro. Al Santísimo Santo [sic] / Con violines, flautas y trompas / El cielo se pasma / Para el Archivo de esta Santa Iglesia / Del Maestro Balius / Año de $1797^{33}$.

[Primera] y segunda clase \# año 1806 / Villancico a cuatro / Al Santísimo Sacramento / obligado de contralto / con violines, oboes, trompas / y bajo / Manjar delicioso \&a. [sic] / del Maestro don Jayme Balius / $\underline{1806}^{34}$.

11 de agosto) y una celebración con rosario, salve y letanías (la tarde del 11 de agosto). Sobre el pago a Esteban Redondo por la composición de estas obras, vid. también ibid., ff. 70v y 71r (nota, 18.01.1806).

31 Las "fiestas de la Corona" debieron de ser las tres ceremonias (una siesta, una misa a la Virgen del Pilar y unas honras fúnebres) costeadas por el Regimiento de la Corona y oficiadas en el Convento de San Agustín "con la mayor solemnidad": Libro de las fiestas de la Capilla de Música de esta Santa Iglesia Catedral de Málaga (manuscrito), ACCM, Sección de Música, signatura 265-1, f. 66r-66v (ceremonias en el Convento de San Agustín, 11-12.10.1805 y 16.10.1805). Las "fiestas" de los Escribanos fueron probablemente la misa y la siesta "con letanía y salve, todo de primera clase" celebradas en el Convento de la Victoria el 15.09.1805: Libro de las fiestas de la Capilla de Música de esta Santa Iglesia Catedral de Málaga (manuscrito), ACCM, Sección de Música, signatura 265-1, f. 65v.

32 ACCM, Sección de Música, signatura 9-5, particellas del acompañamiento instrumental.

33 ACCM, Sección de Música, signatura 9-7, particellas del acompañamiento instrumental.

34 ACCM, Sección de Música, signatura 10-1, particellas de la trompa segunda. Las palabras "y segunda clase \# año 1806" y "1806" (anotación final) están escritas por una mano distinta. El subrayado es original. Vid. también la particella de Tiple (parte superior, antes del primer pentagrama): "Villancico a cuatro al Santísimo del Maestro don Jaime Balius".
Villancico a cuatro. Al Santísimo / Con violines y flautas / Rindan veneraciones. / Para el Archivo de esta Santa Iglesia / Del Maestro Balius / Año de $1797^{35}$.

El análisis de los materiales de estas piezas permite, aparentemente, descartar concordancias entre el villancico [1/104] y Manjar delicioso [8/183]-[12/78], al figurar el año 1806 en las particellas de la composición. No obstante, como en los casos de Afligido hambriento y ¡Oh prodigio! - Sacro convite, la referencia temporal parece aludir a la revisión de la obra para su incorporación al Inventario Capilla [8]. Del análisis de los materiales conservados de Alegres festivos, El cielo se pasma y Rindan veneraciones no puede extraerse información relevante: Aunque las coincidencias en el título hacen difícil pensar que sean obras distintas a las mencionadas en los inventarios, las versiones conservadas no estuvieron destinadas a las "funciones contratadas", sino a ceremonias dependientes del Cabildo, de ahí que se comprasen "para el Archivo de esta Santa Iglesia" ${ }^{36}$. No son estos los únicos casos que ejemplifican la importancia de determinar la filiación original de los materiales en el ACCM: Resulta muy tentador, por ejemplo, identificar las Coplas a cuatro voces a la Virgen de los Dolores [1/102]-[8/178][12/248] con el oratorio Oprime oh gran Monarca, la única obra de Jaime Balius a cuatro voces y dedicada a la Virgen de los Dolores que se custodia en la Sección de Música del

35 ACCM, Sección de Música, signatura 10-4, particellas del acompañamiento instrumental.

36 No es posible, por el momento, establecer la fecha en la que el fondo musical de las "funciones contratadas", propiedad de los músicos de la Capilla como colectivo, junto con parte del fondo privado de algunos profesionales del conjunto, se integró en el archivo de las obras propiedad del Cabildo Catedralicio. La distinta procedencia de ambos fondos está disimulada por la actual organización y catalogación de la Sección de Música del ACCM, pero, como se ha puesto de manifiesto en el cuerpo de texto, es posible rastrearla mediante el análisis de los materiales. Hay algunos villancicos de los que se conservan las dos versiones. Es el caso, por ejemplo de ¿Qué es esto, María? de Jaime Balius (ACCM, Sección de Música, signatura 10-2). El primero de los juegos de particellas, al que he llamado 10-2 [a], perteneció al Cabildo Catedralicio y, por lo tanto, siempre formó parte del Archivo de Música de la Catedral. El segundo juego, al que he denominado 10-2 [b], fue propiedad de la Capilla y es la versión que recogen los inventarios. Las anotaciones realizadas sobre las portadillas del acompañamiento instrumental y del oboe segundo, respectivamente, permiten establecer esta diferencia. En la portadilla del acompañamiento instrumental de 10-2 [a] se lee "Villancico de Concepción / a tres / con violines y obueses / Qué es esto María \&a. / Para el Archivo de esta Santa Iglesia / Del Maestro Balius / Año de 1797". En la portadilla del oboe segundo de la signatura 10-2 [b] se anotó "Primera y segunda clase \# año 1806 / Villancico a tres de Concepción / con violines y flautas / a la Virgen, de tiple / alto y tenor / Qué es esto María / Para la Capilla de Música de la Santa / Iglesia Catedral de Málaga / Del Maestro don Jayme Balius”. Las cursivas son mías. 
Archivo catedralicio malagueño ${ }^{37}$. Sin embargo, ninguno de los materiales conservados de Oprime oh gran Monarca presenta marcas que permitan relacionarlo con la actividad de la Capilla de Música en las "funciones contratadas ${ }^{38}$.

De los villancicos de Balius, a cuatro voces y dedicados al Santísimo, que han sobrevivido en el ACCM, sólo parecen vinculados al fondo de la Capilla los materiales de Manjar delicioso: las anotaciones "1806" y las relativas a la solemnidad de las ceremonias en las que podía interpretarse permiten contextualizarlo en la evaluación llevada a cabo para la conformación del Inventario Capilla [8]. Además de estas aclaraciones, con caligrafía de José Blasco, la portadilla de Manjar delicioso presenta otras, con rasgos caligráficos idénticos a los de los villancicos ;Oh prodigio!-Sacro convite y ¿Qué es esto, María? Estas dos últimas obras debieron de adquirirse, como muy tarde, en 1800, pues ya aparecen mencionadas en el Inventario Capilla [1]. Basándonos en las similitudes caligráficas, podría especularse sobre de la relación entre Manjar delicioso y el asiento [1/104] y, por exclusión, sobre los vínculos entre [3/7-10] y Alegres festivos, El cielo se pasma, En blandas prisiones y Rindan veneraciones. Sin embargo, para poder afirmarlo con rotundidad, también habría que comparar la caligrafía de las particellas propiedad de la Capilla de estos últimos, cosa que es imposible, pues no se conservan. En síntesis, por el momento, no es posible aclarar cuál de los villancicos a cuatro voces de Balius, recogidos en el Inventario Capilla [8], podría ser [1/104] ni si el resto podrían corresponder con [3/7-10]. Sólo puede negarse la vinculación entre [1/104] y Afligido hambriento [8/198]-[12/47] y la concordancia entre [1/104] y otras dos obras en castellano mencionadas en el Inventario [8]: las Coplas a cuatro voces a la Virgen de los Dolores [1/102]-[8/178]-[12/248] y los Gozos a cuatro a San José

37 ACCM, Sección de Música, signatura 10-6.

$38 \mathrm{El}$ análisis de los materiales de $10-6$ permite concluir que, bajo esta signatura, hay en realidad dos versiones de la composición, una en particellas y otra en partitura, probablemente elaboradas en momentos distintos. La versión en particellas, a la que he llamado 10-6 [a], está fechada en 1781: "1781. Acompañamiento / Oratorio a la Virgen / de los Dolores / Balius" (10-6 [a], particellas del acompañamiento instrumental). La versión en partitura, a la que he llamado 10-6 [b], perteneció a José María Velasco, violín de la Capilla de Música: "Este borrador es de José María Velasco" (10-6 [b], sin foliar, recto del primer folio, parte superior de la partitura, antes del primer sistema) y "José María Velasco [rúbrica]" (10-6 [b], recto del último folio, esquina superior derecha). Velasco no se incorporó a la Capilla hasta julio de 1819: Libro de las fiestas de la Capilla de Música de esta Santa Iglesia Catedral de Málaga (manuscrito), ACCM, Sección de Música, signatura 265-1, f. 170r (nota sobre la contratación de José Laguna y José Velasco, julio de 1819). Esta circunstancia, unida al formato de los materiales (no adecuado para la interpretación), hacen improbable que 10-6 [b] sea la versión incluida en los inventarios.
[3/53]-[8/216]-[12/247], catalogados en la actualidad con el título Pues sois santo sin igual.

Tampoco es fácil establecer cuáles son los "dos villansicos del Maestro Balius a cuatro" [12/49-50]. Una vez descartadas las concordancias trazadas para los otros villancicos a cuatro del compositor, mencionados en el Inventario Capilla [12], puede concluirse que debieron de ser dos de estos tres: El cielo se pasma [8/187], En blandas prisiones [8/182] o Rindan veneraciones [8/181]. Aparentemente, Rindan veneraciones [8/181] y En blandas prisiones [8/182] son los candidatos más firmes, porque el asiento doble [8/181-182] debería tener su equivalente en el asiento doble [12/49-50] y porque, aunque El cielo se pasma también aparece en el Inventario Capilla [8] en otro asiento doble, [8/187-188], junto con Alegres festivos, Capilla [12] lista Alegres festivos en un asiento simple, [12/88].

\section{CONCLUSIONES}

A lo largo de este artículo se han puesto de manifiesto las dificultades que para la identificación de autores y composiciones y el establecimiento de concordancias presentan los doce inventarios redactados por los músicos de la $\mathrm{Ca}$ pilla de la Catedral de Málaga en el primer tercio del siglo XIX. Basándome en el estudio y el cruce de la información proporcionada en los distintos listados sobre la autoría, el título, la tipología compositiva, la advocación, la plantilla y otros detalles de las piezas, así como en los datos recabados mediante el análisis de, por un lado, otras fuentes asociadas al desarrollo de las "funciones contratadas" y, por otro, los materiales conservados de las obras mencionadas en los inventarios, he podido salvar una parte considerable de estas dificultades: Además de los 32 asientos, repartidos en 4 inventarios, en los que se mencionan explícitamente obras en castellano de Jaime Balius (vid. Apéndice 1 de ese trabajo), he conseguido identificar otros tres asientos que, pese a carecer de atribución de autoría (o ser esta confusa), también recogen piezas en castellano del compositor. Asimismo, he logrado establecer concordancias sólidamente fundamentadas para 30 de los 35 asientos, identificar en ellos 13 piezas distintas y relacionar con un título concreto 10 de ellas. Estas mismas estrategias también han hecho posible determinar qué papeles con obras en castellano de Balius, empleados por la Capilla en las "funciones contratadas", se conservan en la actualidad en la Sección de Música del Archivo del Cabildo Catedralicio de Málaga. Los resultados de la investigación están condensados en el Apéndice 2 de este artículo. 


\section{APÉNDICE 1}

Inventarios Capilla [1]-[12]

Asientos con obras en castellano atribuidas expresamente a Jaime Balius

\section{Inventario [1]}

[1/102-103]

$[1 / 104]$

$[1 / 105]$

$[1 / 106]$

[1/107]

\section{Inventario [3]}

[3/7-12]

$[3 / 52-53]$

\section{Inventario [8]}

$[8 / 171]$

[8/178]

[8/180]

$[8 / 181-182] \quad 32^{\circ}$

[8/183]

$[8 / 187-188] \quad 36^{\circ}$

[8/198]

[8/212]

[8/216]

\section{Inventario [12]}

$\begin{array}{ll}{[12 / 45]} & 3^{\circ} \\ {[12 / 47]} & 5^{\circ} \\ {[12 / 49-50]} & 7^{\circ} \\ {[12 / 78]} & 34^{\circ} \\ {[12 / 79]} & 35^{\circ} \\ {[12 / 88]} & 43^{\circ}\end{array}$

$22^{\circ}$

$29^{\circ}$

$31^{\circ}$

$33^{\circ}$

$43^{\circ}$

$56^{\circ}$

$60^{\circ}$
Dos de Dolores de Balius y Redondo

Villan $[\mathrm{ci}]^{\mathrm{co}}$. a cuatro al Sacramento de Balius

Uno [un villancico] a tres a la Virgen, del Maestro Balius

Otro [villancico] a tres de Balius

Un Duo al Sacramento de Balius
087

Por seis Villan[ci] ${ }^{\text {cos }}$, cuatro de Valius y dos de Pons

000 Dos gozos del Maestro Balius a San José regalados por el señor [Pedro] Despax

Villan[ci] ${ }^{\mathrm{co}}$. a tres del señor Valius Los frios La escarcha, [para] segunda clase

Coplas a la Virgen de los Dolores a cuatro voces, del señor Balius, para primera y segunda clase

Vill[anci] ${ }^{\text {co }}$ a tres Ques [sic] esto, Maria del señor Balius, [para] primera y segunda [clases]

Dos $\mathrm{VV}^{\mathrm{s}}$. [villancicos] a cuatro: [el] primero Rindan Veneraciones [y el] segundo En blandas prisiones, del señor Balius, [para] primera y segunda clase

Vill[anci ${ }^{\mathrm{co}}$. a cuatro Manjar Delicioso, del señor Balius, [para] primera y segunda [clases]

Dos Vill[anci] $]^{\text {cos }}$. a cuatro: el primero El cielo se pasma [y el] segundo Alegres festivos, del señor Balius, [para] primera y segunda clase

Vill[anci ${ }^{\mathrm{co}}$. a cuatro Hafligido ambriento, del Maestro Balius, para primera clase

0020

Vill[anci] ${ }^{\mathrm{co}}$. a dúo Sacro Combite, del Maestro Balius, [para] segunda clase

Gozos a cuatro al señor San José del Maestro Balius, [para] primera y segunda clase

$3^{\circ} \quad$ Villansico a tres del Maestro Balius

$5^{\circ} \quad$ Vallansico [sic] a cuatro del Maestro Balius. Afligido

$7^{\circ} \quad$ Dos villansicos del Maestro Balius a cuatro

$34^{\circ} \quad$ Villansico a cuatro del Maestro Balius. El eielo se pasma. Manjar

$35^{\circ} \quad$ Villansico a tres del Maestro Balius. Que es esto Maria

$43^{\circ} \quad$ Villansico a cuatro del Maestro Balius. Alegrate, festivos 
[12/172]

62 Aria a dúo de Balius

$[12 / 247]$

1 Gozos a cuatro de Balius

$[12 / 248]$

Coplas a cuatro de Balius

\section{APÉNDICE 2}

Inventarios Capilla [1]-[12]

Obras en castellano de Jaime Balius

Afligido hambriento. Villancico a cuatro

[8/198]: "Vill[anci] ${ }^{\text {co }}$. a cuatro Hafligido ambriento, del Maestro Balius, para primera clase.

[12/47]: "Villansico a cuatro del Maestro Balius". Añadido a lápiz: "Afligido".

ACCM, Sección de Música: Afligido hambriento, alégrate y canta. Villancico a cuatro con violines, oboes, trompas y bajo, signatura 9-4.

Alegres festivos. Villancico a cuatro

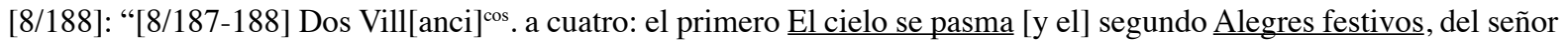
Balius, [para] primera y segunda clase".

[12/88]: "Villansico a cuatro del Maestro Balius". Añadido a lápiz: "Alegrate [sic] festivos".

ACCM, Sección de Música: Alegres, festivos. Villancico a cuatro al Santísimo Sacramento con violines, oboes y trompas, signatura 9-5.

Observaciones: La versión conservada no parece vinculada a las "fiestas" de la Capilla.

Coplas a cuatro voces a la Virgen de los Dolores

[1/102]: “[1/102-103] Dos de Dolores de Balius y Redondo".

[8/178]: "Coplas a la Virgen de los Dolores a cuatro voces, del señor Balius, para primera y segunda clase".

[12/248]: "Coplas a cuatro de Balius".

ACCM, Sección de Música: Aparentemente no se conservan.

El cielo se pasma. Villancico a cuatro

[8/187] "[8/187-188] Dos Vill[anci] $]^{\text {cos }}$. a cuatro: el primero El cielo se pasma [y el] segundo Alegres festivos, del señor Balius, [para] primera y segunda clase".

ACCM, Sección de Música: El cielo se pasma. Villancico a cuatro al Santísimo Sacramento con violines, oboes y trompas, signatura 9-7.

Observación: Las versión conservada no parece vinculada a las "fiestas" de la Capilla.

En blandas prisiones. Villancico a cuatro

[8/182]: “[8/181-182] Dos VV'. [villancicos] a cuatro: [el] primero Rindan Veneraciones [y el] segundo En blandas prisiones, del señor Balius, [para] primera y segunda clase".

Posiblemente [12/50]: "[12/49-50]: "Dos villansicos del Maestro Balius a cuatro".

ACCM, Sección de Música: Aparentemente no se conserva.

Gozos a tres a San Antonio

[8/186]: “[8/185-186] "Gozos a San José a tres por don P.[edro] D.[espax] y B.[eltri] [sic], para primera y segunda [clase], y sirven para San Antonio por tener las voces duplicadas".

[12/252]: "Id. [gozos] a seis tres sin autor".

ACCM, Sección de Música: Aparentemente no se conservan.

Observaciones: Misma música que los Gozos a tres a San José [3/52]-[8/185]-[12/252]. 
Gozos a tres a San José

[3/52]: “[3/52-53] Dos gozos del Maestro Balius a San José regalados por el señor [Pedro] Despax".

[8/185]: “[8/185-186] "Gozos a San José a tres por don P.[edro] D.[espax] y B.[eltri] [sic], para primera y segunda [clases], y sirven para San Antonio por tener las voces duplicadas".

[12/252]: "Id. [gozos] a seis tres sin autor".

ACCM, Sección de Música: Aparentemente no se conservan.

Observaciones: Misma música que los Gozos a tres a San Antonio [8/186]-[12/252].

Los fríos, la escarcha. Villancico a tres

[1/106]: "Otro [villancico] a tres de Balius".

[8/171]: "Villan[ci] ${ }^{\text {co }}$ a tres del señor Valius Los frios La escarcha, [para] segunda clase".

[12/45]: "Villansico a tres del Maestro Balius".

ACCM, Sección de Música: Los fríos, la escarcha. Villancico segundo, primer nocturno, signatura 9-9.

Observación: La versión conservada no parece vinculada a las "fiestas" de la Capilla.

Manjar delicioso. Villancico a cuatro [al Santísimo]

[8/183]: "Vill[anci] ${ }^{\text {co }}$. a cuatro Manjar Delicioso, del señor Balius, [para] primera y segunda [clases]".

[12/78]: "Villansico a cuatro del Maestro Balius. Añadido y tachado a lápiz: "El cielo se pasma”. Añadido a lápiz "Manjar", sobre las palabras "El cielo se pasma".

ACCM, Sección de Música: Manjar delicioso. Villancico a cuatro al Santísimo Sacramento obligado de contralto con violines, oboes, trompas y bajo, signatura 10-1.

[iOh prodigio!] Sacro convite. Villancico a dúo

[1/107]: "Un Duo al Sacram ${ }^{\text {to }}$. de Balius".

[8/212]: "Vill[anci] $]^{\text {co }}$ a dúo Sacro Combite, del Maestro Balius, [para] segunda clase".

[12/172]: “Aria a dúo de Balius".

ACCM, Sección de Música: ;Oh prodigio!, signatura 10-10.

[Pues sois santo sin igual] Gozos a cuatro al Señor San José

[3/53]: “[3/52-53] Dos gozos del Maestro Balius a San José regalados por el señor [Pedro] Despax".

[8/216]: "Gozos a cuatro al señor San José del Maestro Balius, [para] primera y segunda clase”.

[12/247]: "Gozos a cuatro de Balius".

ACCM, Sección de Música: Pues sois santo sin igual, signatura 10-5.

¿Qué es esto, María? Villancico a tres

[1/105]: "Uno [un villancico] a tres a la Virgen, del Maestro Balius".

[8/180]: "Vill[anci] $]^{\text {co }}$ a tres Ques [sic] esto, Maria del señor Balius, [para] primera y segunda [clases]".

[12/79]: "Villansico a tres del Maestro Balius". Añadido a lápiz: "Que es esto Maria".

ACCM, Sección de Música: ¿Qué es esto, María? Villancico a tres de Concepción con violines y flautas a la Virgen, signatura 10-2.

Observaciones: El ACCM conserva dos versiones de esta pieza. La versión que se empleó en las "funciones contratadas" es la versión en particellas, a la que he denominado 10-2 [b].

Rindan veneraciones. Villancico a cuatro

[8/181]: "[8/181-182] Dos VV". [villancicos] a cuatro: [el] primero Rindan Veneraciones [y el] segundo En blandas prisiones, del señor Balius, [para] primera y segunda clase".

Posiblemente [12/49]: "[12/49-50]: "Dos villansicos del Maestro Balius a cuatro".

ACCM, Sección de Música: Rindan veneraciones. Villancico a cuatro al Santísimo con violines y flautas, signatura $10-4$.

Observaciones: La versión conservada no parece vinculada a las "fiestas" de la Capilla. 


\section{BIBLIOGRAFÍA}

Ballús Casóliva, Glòria, La Música a la col-legiata basílica de Santa Maria de la Seu de Manresa: 1714-1808. Dades documentals per a la seva reconstrucció amb una aproximació al repertori litúrgic conservat. Tesis Doctoral, Universidad Autónoma de Barcelona, 2004, 3 vols., http://hdl.handle.net/10803/5193

Bedmar Estrada, Luis Pedro, La música en la Catedral de Córdoba a través del Magisterio de Jaime Balius y Vila (1785-1822). Granada, Centro de Documentación Musical de Andalucía, 2009.

Llordén, Andrés (OSA), "Inventario musical de 1770 en la Catedral de Málaga", Anuario Musical, 24 (Barcelona, 1969): 237-246.

Martín Moreno, Antonio (dir.), Catálogo del Archivo de Música de la Catedral de Málaga, Granada, Junta de Andalucía, 2003, 2 vols.

Martín Quiñones, $\mathrm{M}^{\mathrm{a}}$ Ángeles, La música en la Catedral de Málaga durante la segunda mitad del siglo XVIII: La vida y obra de Jaime Torrens. Tesis Doctoral inédita, Universidad de Granada, 1997, 3 vols.

Naranjo, Luis, "Francés de Iribarren Echevarría, Juan»", Emilio Casares Rodicio (dir.), Diccionario de la Música Española e Hispanoamericana. Madrid, SGAE, 1999, vol. 5: 235-241.

Torre Molina, María José de la, La música en Málaga durante la Era Napoleónica (1808-1814). Málaga, Universidad de Málaga y Ayuntamiento de Málaga, 2003, 2 vols.

Torre Molina, María José de la, "Música, poder y propaganda en las honras malagueñas por los héroes de Bailén (1808)”, Boletín de Arte, 29 (Málaga, 2008): 215-237.
Torre Molina, María José de la, “Circulación y recepción de la música de Francisco Javier García Fajer en España: el caso de la Catedral de Málaga”, Miguel Ángel Marín López (ed.), La ópera en el templo. Estudios sobre el compositor Francisco J. García Fajer, Logroño, Instituto de Estudios Riojanos e Institución Fernando El Católico, 2010a: 237-285.

Torre Molina, María José de la, "La Catedral de Málaga como modelo de estudio de la música en el ámbito catedralicio español e hispanoamericano: logros, perspectivas y retos", Antonio García-Abásolo (ed.), La música en las catedrales andaluzas y su proyección en América, Córdoba, Universidad de Córdoba, 2010b: 299-341.

Torre Molina, María José de la, "El inventario de 1806-1814 y el repertorio de la Capilla de Música de la Catedral de Málaga en las funciones contratadas de principios del siglo XIX (I)”, Boletín de Arte, 30-31 (Málaga, 2009-2010): 239-279.

Torre Molina, María José de la, "El inventario de 1806-1814 y el repertorio de la Capilla de Música de la Catedral de Málaga en las funciones contratadas de principios del siglo XIX (II)", Boletín de Arte, 32-33 (Málaga, 2011-2012): 149-176.

Torre Molina, María José de la, "Por ser propio de los individuos de la Capilla: inventarios de bienes y construcción de repertorios en la España del primer tercio del siglo XIX. El caso de la capilla de música de la Catedral de Málaga”, Revista de Musicología, XXXIX-2 (Madrid, 2016): 455-482.

Recibido: 23.01.2017

Aceptado: 20.09.2017 